\title{
Cranioschisis and Anencephaly in a Dog - Challenging Etiology
}

\author{
Idelvânia dos Anjos Nonato', Marina Ribeiro Ferreira², Jéssica Lelis de Miranda', \\ Heloísia Maria Bressan Braz ${ }^{3}$ \& João Paulo Machado4
}

\begin{abstract}
Background: Congenital anomalies involve changes that may occur in the central nervous system during the period from gestation until birth. The present study reports a case of cranioschisis and anencephaly in a dog and aims to discuss the possible etiologies of these malformations in dogs.

Case: A pinscher bitch was referred to a private veterinary clinic in the city of Muriaé - MG, for routine consultation and gestational diagnosis, which was carried out by ultrasound on the 39th day. Routine care was extended until delivery, and clinical and complementary examinations were performed to assess the health of the female dog and that of the fetuses. Vital parameters and morphological characteristics showed that all fetuses had present cardiac activity, correctly formed bone skeleton, definition of the head, trunk and limbs, presence of fetal movements, definition of the hepatic region and hepatic parenchyma typically hypoechoic, hyperechoic pulmonary parenchyma, and visualization of the stomach and bladder. The delivery lasted two hours, and three female puppies were born. A macroscopically significant cranial alteration was observed in the second pup; it was located in the middle line of the skull unprotected by skin. The placenta was dark in color. The puppy's respiratory activity was present, but with dyspnea, body movements were limited and presented hypothermia. In the first $24 \mathrm{~h}$, the female puppy was fed homemade milk compound through a syringe because of difficulty in performing the suction movement. Delay in urination and defecation were also observed in relation to the other neonates. Before completing the first $48 \mathrm{~h}$ of birth, this newborn died, and his cadaver was submitted for necropsy. The necropsy procedure identified the presence of acrania (partial absence of the bones of the skull), aplasia of the skin of the eyes, meningoencephalocele demonstrating that the meningeal formed an external pocket, and partial anencephaly and exencephaly (brain outside the cranial cavity). Subsequently, organ samples were sent for evaluation by means of qualitative PCR for canine herpesvirus and the result was negative.

Discussion: Anencephaly is a result of erroneous closure of the neural sulcus, causing partial formation or no formation of the brain. The etiology ranges from environmental factors or teratogenic effects such as radiation, viruses, toxic substances, maternal diseases, maternal genotype, enzymatic activity, and fetal susceptibility. CaHV-1 type 1 canine herpesvirus has been reported to cause abortion, fetal mummification, stillbirth, the birth of weak pups, or neonatal death. The anomalies involving cranial and encephalic malformation have a multifactorial etiology, which made it difficult to identify the actual cause that led the pup to present the reported characteristics. Despite the negative result of the PCR test, Canine herpesvirus (CaHV-1 type 1), as well as the use of some drugs during pregnancy, are major causes of this disease.
\end{abstract}

Keywords: anomalies, etiology, histopathology, multifactorial, necropsy, PCR. 


\section{INTRODUCTION}

Inside the cavity of the skull, attached to the base of the cranium is the brain and that includes the brain, cerebellum, protuberance and rachian bulb [14]. Congenital anomalies are changes that may occur in the brain during the period from gestation until birth, which manifests with age $[1,2]$. Due to the complexity of embryological development, it is not uncommon or unusual for an abnormal development of the encephalon to occur [11].

The dimensions of the skull of dogs can vary in length and width, based on the type of breed and body size [20]. The neural tube originates from the neural plaque fused to the neuroepithelium along the midline in the embryonic stage $[9,14]$. An error in this junction leads to poor formation of the encephalon, such as anencephaly characterized by poor formation in the cranial portion of the neural tube, a phenomenon called neurulation, which is not very common in dogs $[7,13,14]$. However, when this abnormality occurs, the lethal form is the most common where the anencephalic fetus can be stillborn or live for a few hours or days [18].

Another genetic deformity that can occur is cranioschisis. This occurs due to lack of bone production in the midline of the skull, which leads to a direct opening, exposing the meningeal and placing it in direct contact with the skin of the head. It is common to observe the projection of the cephalic tissue showing an opening at the defect [13].

The etiology is usually linked to genetic causes, to environmental and multifactorial factors, since the central nervous system of animals is highly susceptible to teratogenic agents. When this occurs, it is impossible to confirm the cause as the occurrence of cranioschisis is mainly associated with meningocele or meningoencephalocele. In cats, it is commonly associated with the use of the antifungal griseofluvin at the beginning of gestation, that leads to malformation in the kittens [19].

The present study reports a case of cranioschisis and anencephaly in a dog and aims to discuss the possible etiologies of these malformations in dogs.

\section{CASE}

A pinscher breed dog was referred for veterinary care at a private veterinary clinic in Muriaé-MG. During the first clinical examination, pregnancy was confirmed on the 39th day of gestation by ultrasound.
Gestational follow-up was extended until delivery, and clinical and complementary examinations were performed to evaluate the health status of the female dog and the fetuses, as well as possible changes related to gestational and fetal development. Ultrasound examinations performed between the 39th and 50th day of gestation allowed the estimation of the presence of three fetuses in the uterus of the bitch. The vital parameters and morphological characteristics of this study allowed us to conclude that all the fetuses had cardiac activity, bone formation, definition of trunk head and limbs, fetal movements, definition of the hepatic region and hepatic parenchyma typically hypoechoic, hyperechoic pulmonary parenchyma, and visualization of the stomach and bladder. Hematological evaluations included blood counts and biochemical analysis of the dog performed at the first veterinary clinic and in the days leading up to the delivery. The expected limits of the reference values for the species were observed. On entering labor, the dog took approximately two hours to deliver all three female puppies. It was possible to notice a macroscopically significant cranial alteration in the second pup, consisting of a soft, ovoid mass of the skin located in the midline of the skull. The skull cap was markedly smaller when compared to that of the other of springs of the same brood. In addition to the cranial changes, placental changes were observed, which presented a darker coloration. Breathlessness, decreased body motor activity, and hypothermia were observed. Twenty-four h after birth, the puppy with the changes described above was fed homemade compound through a syringe, because of difficulty in performing the suction movement. There was also a delay in urination and defecation compared to other newborns. Body temperature remained low, respiration remained dyspneic, and motor difficulties were still noticeable. Before completing $48 \mathrm{~h}$ of life, the newborn female died. Subsequently, necropsy was performed. Samples of the lung, heart, kidney, liver, brain, and cerebellum were collected. It is important to note that the mother of the puppy described above, did not register any clinical, nutritional, or behavioral changes.

\section{DISCUSSION}

The necropsy examination showed, diagnosis of acrania, a partial absence of the skull bones (Figure 1), aplasia of the ocular skin, meningoencephalocele, showing that the meningeal formed an external pocket, 


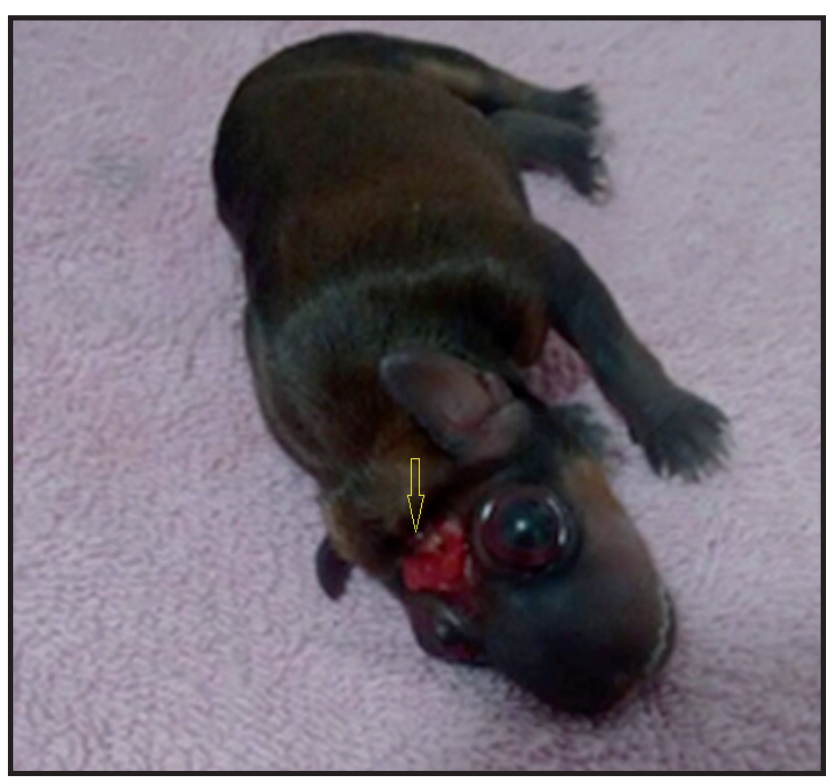

Figure 1. Diagnosis of acrania, a partial absence of the skull bones (seta).

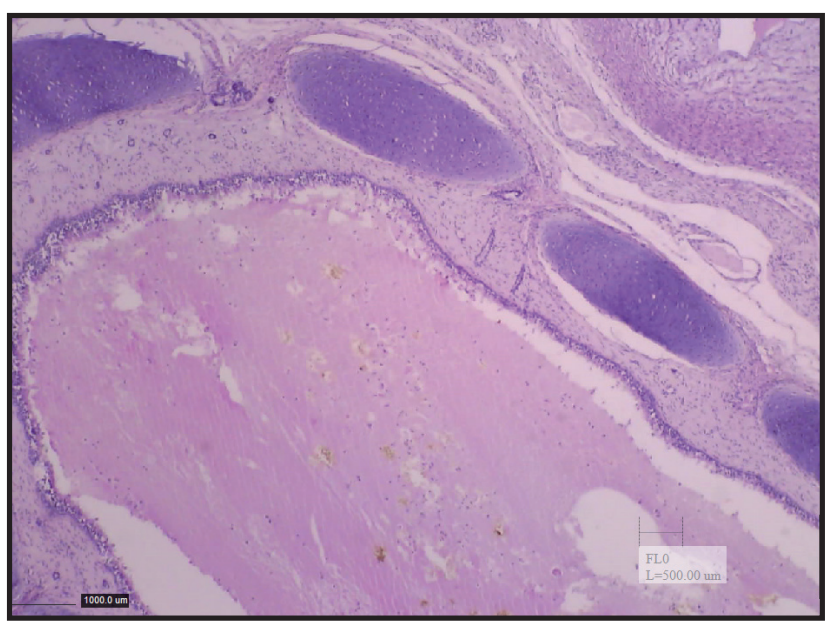

Figure 3. Presence of exogenous contents in the trachea [H\&E; Obj.100x].

partial anencephaly and exencephaly, which shows the brain outside the cranial box. The macroscopic findings resemble those described by Hisinga et al. [9] in humans and in dogs. In the histopathological evaluation, the liver was congested and the lung presented edema and diffuse fibrinous exudation, obstructing the alveoli and bronchioles, and presence of exogenous contents in the trachea (Figures $2 \& 3$ ). These alterations may suggest aspiration by a false pathway, since the baby was fed by bottle and also presented palatoschisis (Figure 4). Centenaro et al. [3] and colleagues described this change as a variable length longitudinal fusion defect that affects the bone and mucosa of the hard palate line. One of the main results of this alteration is starvation, since patients with this defect present an inability to create negative pressure in the mouth, resulting in insufficient suction. This favors the passage



Figure 2. Histopathological examination shows congestion and pulmonary edema and diffuse fibrous exudation, obstructing the alveoli and bronchioles [H\&E; Obj.100x].

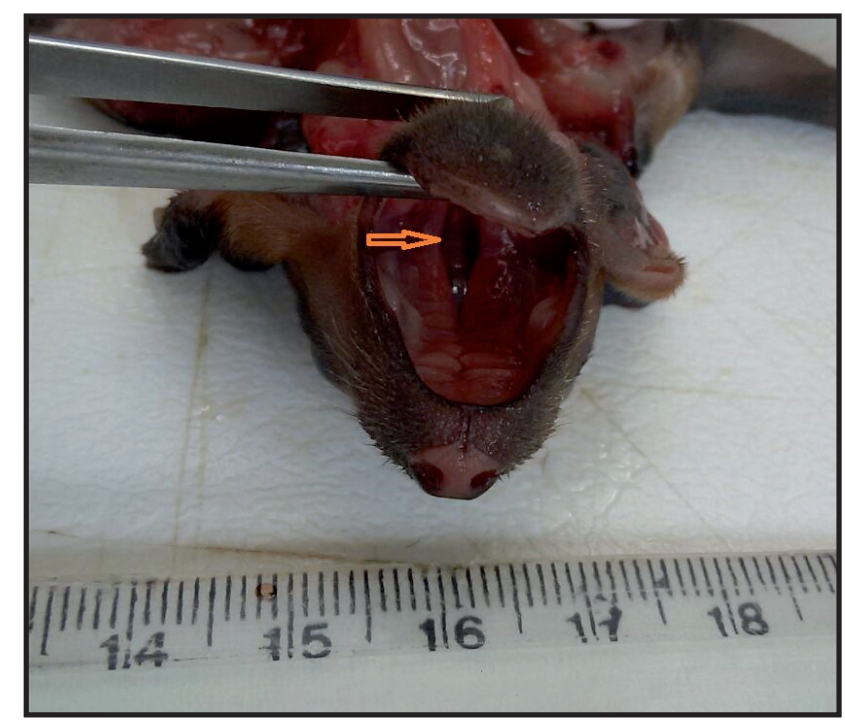

Figure 4. Macroscopic presentation. Palatoschisis communication of the oral cavity with the nasal cavity (Seta).

of food and microorganisms from the oral cavity to the airways, reaching the lungs, and thus causes death from pneumonia [8].

Measurements were made establishing a comparison between the length and weight of the newborns, confirming a variation always showing lower values for the cranioschisis and anencephaly (N1) neonates than for the other two neonates of the same litter (N2 and N3). The comparison of specific areas of the skull was reported using four different parameters. Parameter (1) refers to the measurement of the largest longitudinal cross-sectional diameter of each newborn's skull. The results for N1, N2, and N3 were $75 \mathrm{~mm}, 117 \mathrm{~mm}$ and $111 \mathrm{~mm}$ respectively. Parameter (2) reports the extension that runs through the parietal bones between the upper area of the temporal bones, the values obtained are $40 \mathrm{~mm}$ for $\mathrm{N} 1$ and $56 \mathrm{~mm}$ for 
N2 and N3. Parameter (3) reports the greatest transverse length of the cranium of each neonate, so the results were described in order N1, N2 and N3 with values of $45 \mathrm{~mm}, 61 \mathrm{~mm}$ and $56 \mathrm{~mm}$. The last parameter (4) made a relation between the three neonates pointing the extension between the crest of the neck to the most rostral line of the incisive bones determining N1, N2, and N3 with $25 \mathrm{~mm} 42 \mathrm{~mm}$ and $35 \mathrm{~mm}$ respectively. The weight was recorded on the same date as the described parameters, reporting $150 \mathrm{~g}$ for N1, $190 \mathrm{~g}$ for $\mathrm{N} 2$ and $170 \mathrm{~g}$ for N3. The extension between the first cervical vertebra to the last sacral vertebra has also been reported and its respective values for N1, N2, and $\mathrm{N} 3$ were $90 \mathrm{~mm}, 133 \mathrm{~mm}$ and $145 \mathrm{~mm}$ respectively.

Anencephaly is a result of erroneous closure of the neural groove, in this way it is common to have no formation of the encephalon, as well as failure in the formation and closure of the skull, which corroborates with Wammes et al. [21] who reported anencephaly in dogs confirming the absence of traces of brain formation.

According to the literature, congenital defects show a pathological state that appears concomitantly, and may occur after conception during pregnancy [2] or after birth as the case reported in the current study.

Pups with anencephaly that survive for a short period show a functional brainstem, thus breathing and spontaneous reflexes are visible, and in some cases, some can suck-feed. The puppies remain unconscious and even with intensive and special care they die within two days [6], as occurred in the present study.

In addition to environmental factors, teratogenic effects such as radiation, viruses, toxic substances, maternal diseases, maternal genotype, enzymatic activity, and fetal susceptibility are included as causes of malformation [1]. Among these factors, nutritional deficiencies or excesses during gestation can be mentioned. Obese dogs have fewer offspring per litter with higher neonatal mortality rates, skeletal deformity, and cardiac valvular stenosis being observed [16,17]. The use of drugs during pregnancy can also induce embryonic or fetal death, as well as malformations due to intoxication, such as the use of griseofulvin and other antifungals, progestogens, steroids, and antibiotics [5]. Another important factor is the genetic defects that lead to hereditary and non-hereditary disorders, leading to skeletal malformations, cardiac malformations and palatoschisis $[12,10]$. Endocrine alterations can also lead to poor formation and death of fetuses in gestation, as in cases of hypothyroidism in dogs [15]. Contamination by bacteria, such as Brucella spp. and viruses such as CaHV-1 are likely causes.

CaHV-1 is a double-stranded DNA virus belonging to the subfamily Alphaherpesvirinae [4]. There are reports that CaHV-1 type can cause abortion, fetal mummification, stillbirth, the birth of weak pups, or neonatal death $[4,7]$. Samples of the puppy mentioned in the present study were sent for evaluation by means of qualitative PCR for canine herpesvirus, but the result was negative.

Some concepts change according to the literature. Most studies classify anencephaly as the absence of the encephalus. However, when there is a functioning neural tissue, it is called meroanencephaly (absence of part of the encephalon) [21], which was not observed in the case reported in the present study.

As described in the present study, the anomalies involving cranial and encephalic malformation have a multifactorial etiology, which made it difficult to identify the real cause of the above-mentioned case. Even though PCR results were negative in this case, CaHV-1 type 1 and the use of some drugs during pregnancy constitute major causes of this disease. Consequently, studies related to the identification of the causal agent when there is no hereditary factor involved may prevent this condition in future pregnancies.

\section{MANUFACTURER}

${ }^{1}$ Tecsa - Tecnologia em Sanidade Animal. Belo Horizonte, MG, Brazil.

Declaration of interest. The authors report no conflicts of interest. The authors alone are responsible for the content of the paper

\section{REFERENCES}

1 Alberto M.V.L., Galdos A.C.R., Miglino M.A. \& Santos J.M. 2010. Anencefalia: Causas de uma malformação congênita. Revista Neurociências. 18(2): 244-248.

2 Bianco M.H.B.C. 1996. Monitorização de malformações congenitas. v.1. Cadernos de Divulgação Cultural. São Paulo: Roca, 105p.

3 Centenaro V., Dutra L. \& Rossato C. 2011. Fenda palatina em animais domésticos - revisão bibliográfica. In: XVI Seminário Interinstucional de Ensino, Pesquisa e Extensão. Unidade do Desenvolvimento Regional (Cruz Alta, Brazil). pp.1-4. 
4 Decaro N., Martella V. \& Buonavoglia C. 2008. Canine adenoviruses and herpesvirus. Veterinay Clinical Small Animal. 38: 799-814.

5 Dumon C. 2005. Patologia Neonatal do Filhote. Os primeiros 15 dias. In: Prats A. (Ed). Neonatologia e Pediatria: Canina e Felina. São Caetano do Sul: Interbook, pp.126-151.

6 Fishman M.A. \& Villareal G.B. 2008. Anencephaly and encephalocele. Uptodate. 32(1): 124-28.

7 Greene C.E. 2013. Canine herpesvirus infection. In: Greene C.E. (Ed). Infectious Diseases of the Dog and the Cat. 4th edn. St. Louis: Saunders, pp.48-54.

8 Hette K.\& Rahal S.C. 2004. Defeitos congênitos do palato em cães: revisão da literatura e relato de três casos. Clínica Veterinária. 9(50): 30-40.

9 Hisinga M., Reinacher M., Nagel S.\& Herden C. 2010. Anencephaly in a German Shepherd Dog. Veterinary Pathology. 47(5): 948- 951.

10 Johnston S.D. \& Raksil S. 1987. Fetal loss in the dog and cat. Veterinay Clinics of North America: Small Animal Practice. 17: 535-554.

11 Lopez A.C. 2005. Tratado de Clínica Médica. v.1. 2.ed. São Paulo: Roca, 308p.

12 Louw G.J. 1983. Osteochondrodysplasia in a litter of bulldog puppies. Journal of the South African Veterinary Association. 54(2):129-131.

13 Mcgavin M.D. \& Zachary J.F. 2009. Sistema nervoso. In: Zachary J.F. (Ed). Bases da Patologia em Veterinária. 4.ed. Rio de Janeiro: Editora Elsevier, pp.833-971.

14 Moore K.L. \& Persaud T.V.N. 2004. Embriologia Clínica. 7.ed. São Paulo: Elsevier, 609p.

15 Panciera D.L., Purswell B.J. \& Kolster K.A. 2007. Effect of short-term hypothyroidism on reproduction in the bitch. Theriogenology. 68: 316-321.

16 Prats A. 2005. Período neonatal. In: Prats A. (Ed). Neonatologia e Pediatria: Canina e Felina. São Caetano do Sul: Interbook, pp.30-41.

17 Peterson M.E. 2011. Neonatal mortality. In: Peterson M.E. \& Kutzler MA. (Eds). Small Animals Paediatrics: the first 12 months of life. St. Louis: Saunders, pp.82-87.

18 Ramirez-Espitia J.A., Benavides F.G., Lacasãna-Navarro M., Martínez J.M., Garcia A.M. \& Benach J. 2003. Mortalidad por defectos del tubo neural en México 1980-1997. Salud pública México. 45: 355-364.

19 Scherer F., Soares F.J., Pereira H.S., Melo T.L., Rodrigues E.H.S., Libmann E.R., Venturoso O.J., Vieira N.T. \& Schons S.V. 2014. Craniosquise e Meningocele em Ovinos. In: II Encontro Internacional de Sanidade de Animais de Produção (ENDIVET) - VII Encontro Nacional de Diagnóstico Veterinário (ENISAP) - [Cuiabá, Brazil]. pp.1-2.

20 Silva M., Sterman F. \& Almeida A. 2007. Mensuração ultra-sográfica das dimensões do crânio fetal em gestações normais em cadelas da raça boxer e sua relação com a idade gestacional. Brazilian Journal of Veterinary Research and Animal Science. 44(supl.1): 25-29.

21 Wammes J.C.S., Filadelpho A.L., Birck A.J., Peres J.A., Pinto e Silva J.R.C., Guazzelli Filho J. \& Barcelos R.P. 2013. Anencefalia, macroglossia e fenda labial em cão: relato de caso. Revista Científica Eletrônica de Medicina Veterinária. 11(21): 1-8. 